American Journal of Immunology 7 (4): 62-67, 2011

ISSN 1553-619X

(C) 2011 Science Publications

\title{
The Impact of Helicobacter Pylori Infection on Lung Function and Severity of Bronchial Hyperresponsiveness in Subjects with Allergic Asthma
}

\author{
${ }^{1}$ Jordan B. Minov, ${ }^{1}$ Jovanka Karadzinska-Bislimovska, \\ ${ }^{2}$ Kristin Vasilevska, ${ }^{1}$ Snezana Risteska-Kuc, ${ }^{1}$ Saso Stoleski and ${ }^{1}$ D. Mijakoski \\ ${ }^{1}$ Department of Cardiorespiratory Functional Diagnostics, \\ Institute for Occupational Health of R. Macedonia, \\ WHO Collaborating Center and GA ${ }^{2}$ LEN Collaborating, \\ Center II Makedonska Brigada 43, 1000 Skopje, R. Macedonia \\ ${ }^{2}$ Institute for Epidemiology and Biostatistics, Skopje, R. Macedonia, Jordan B. Minov
}

\begin{abstract}
Problem statement: There is evidence that Helicobacter pylori $(H$. pylori) infection may modify immune response and decrease the risk of asthma and other allergic diseases, as well. Approach: To assess the impact of $H$. pylori infection on lung function parameters and severity of Bronchial Hyperresponsiveness (BHR) in subjects with allergic asthma. A cross-sectional study including $38 \mathrm{H}$. pylori positive subjects with allergic asthma (18 males and 20 females, aged 21-54 years) and an equal number of $H$. pylori negative subjects with allergic asthma studied as a control was carried out. The impact of $H$. pylori infection was assessed by comparison of mean values of spirometric parameters and BHR severity (measured by histamine challenge and expressed as provocative concentration of histamine that causes $\mathrm{FEV}_{1}$ fell by more than $20 \%$ of its base value-PC 20) between two examined groups. Results: The mean values of spirometric parameters were similar in both examined groups. The mean PC20 was lower in the group of subjects with allergic asthma and serological evidence of exposure to $H$. pylori but statistical significance was not reached (2.89 Vs. 3.14 $\left.\mathrm{mg} \mathrm{mL} \mathrm{m}^{-1}, \mathrm{P}>0.05\right)$. Conclusion: Our findings indicate that in cross-sectional analysis there is no significant relation between $H$. pylori seropositivity and the values of spirometric parameters and the degree of BHR severity in subjects with allergic asthma.
\end{abstract}

Key words: Allergic asthma, bronchial hyperresponsiveness, Helicobacter pylori, histamine challenge, spirometric parameters

\section{INTRODUCTION}

There is a strong evidence about the significant increase in the prevalence of allergic asthma and other allergic diseases in the last decades worldwide but the causes of this increase remain largely unknown. Suggested explanations include effects of air pollutants (e.g., diesel exhaust), changes in smoking habits, type of dwelling, family size (i.e., number of siblings), exposure to orofecal infections (Mutius and Sears, 2003; Matricardi et al., 2000; 2002; Salvi et al., 1999; Ball et al., 2000).

There is a recent evidence of inverse association between the Helicobacter pylori (H. pylori) infection and the frequency of allergic asthma and other allergic diseases (Blaser et al., 2008; D'Elios et al., 2009). H. pylori is a Gram-negative bacterium that chronically infects the stomach of more than $50 \%$ of the human population (varying from over $70 \%$ in developing countries to less than $40 \%$ in developed countries) and represents the major cause of gastroduodenal pathologies (Wotherspoon et al., 1991; Parsonnet et al., 1991). H. pylori gastric colonization is followed by mucosa infiltration of polymorphonuclear leukocytes, macrophages and T-helprer type 1 (Th1) lymphocytes with production of interleukin 12 (IL-12) and interferon- $\gamma$ (IFN- $\gamma$ ) (D'Elios et al., 1997). On the other side, allergic asthma and other allergic diseases are orchestrated by T-helper type 2 (Th2) cytokines, such as IL-4 and IL-5 (i.e., Th 2 inflammation) (Barnes, 2003). This type of inflammation may be inhibited by IL-12 and IFN- $\gamma$, i.e., in subjects with allergic asthma

Corresponding Author:Jordan B. Minov, Department of Cardiorespiratory Functional Diagnostics, Institute for Occupational Health of R. Macedonia, WHO Collaborating Center and GA 2 LEN Collaborating, Center, II Makedonska Brigada 43, 1000 Skopje, R. Macedonia Tel: + 38922639637 Fax: + 38922621428 
the typical Th2 response can be redirected toward Th1 by the neutrophil-activating protein of $\mathrm{H}$. pylori (Amedei et al., 2006; Codolo et al., 2008).

In addition, there is a evidence that $\mathrm{H}$. pylori infection is associated with reduced growth in children and with consecutive negative impact on lung development (Perri et al., 1997; Hankinson et al., 1999). The chronic inflammatory response related to $\mathrm{H}$. pylori infection is considered to be a potential risk factor for accelerated age-dependent decline in lung function which may result in lower lung function (Pavord et al., 2006).

To our knowledge, there is only few studies that investigated the association between exposure to $\mathrm{H}$. pylori infection and objective measures of asthma and lung function. on lung function parameters and Severity of Bronchial Hyperresponsiveness (BHR) in subjects with allergic asthma. The present study aimed at investigation of the impact of $\mathrm{H}$. pylori infection on lung function and BHR by comparison of spirometric parameters and degree of BHR severity (expressed as provocative concentration that causes FEV1 fell by more than $20 \%$ of its base value-PC 20) between a group of subjects with allergic asthma with serological evidence of exposure to H. pylori and a group of subjects with allergic asthma and negative serology for $\mathrm{H}$. pylori.

\section{METERIALS AND METHODS}

Study design and setting: A cross-sectional survey was carried out in the Department of Cardiorespiratory Functional Diagnostics at the Institute for Occupational Health of R. Macedonia, Skopje-WHO Collaborating Center for Occupational Health and GA ${ }^{2}$ LEN Collaborating Center in the period May 2011-January 2012.

Study subjects: Fifty four subjects with positive serological finding for $\mathrm{H}$. pylori infection and symptoms suggestive for asthma underwent diagnostic protocol for allergic asthma. Diagnostic criteria met 38 of them, 18 males and 20 females, aged 21-54 years.

In addition, an equal group of $\mathrm{H}$. pylori negative subjects with allergic asthma matched by sex and age to H. pylori positive subjects with allergic asthma were studied as a control. All study subjects were informed about the study and their written consent was obtained.

H. pylori serological status: H. pylori serological status, i.e., quantitative detection of serum immunoglobuline $\mathrm{G}$ ( $\operatorname{IgG}$ ), was evaluated using the Siemens Immulite ${ }^{\mathrm{R}} 1000$ assay (a solid-phase, chemiluminiscent IgG assay) (Siemens, Germany).
Seropositivity was considered in the case of finding of specific $\mathrm{IgG}$ concentration equal or more than 1 $\mathrm{U} / \mathrm{mL}$, while the subjects with serum concentration of specific IgG equal or less than $0.9 \mathrm{U} \mathrm{mL}^{-1}$ were considered as seronegative Immulite $^{\mathrm{R}} 1000$ Chemiluminiscent Technology.

Allergic asthma diagnosis: According to the actual recommendations of the (Bateman et al., 2008), (GINA), a clinical diagnosis of allergic asthma was based on the presence of asthma symptoms (i.e., episodic breathlessness, wheezing, cough and chest tightness), one or more positive skin prick tests to common inhalant allergens, spirometry and on the positive histamine challenge (Dreborg and Frew, 1993).

Skin prick tests: Skin Prick Tests (SPT) to common inhalant allergens were performed in all subjects on the volar part of the forearm using commercial allergen extracts (Torlak, Serbia and Montenegro) of birch (5000 PNU), grass mixed (5000 PNU), plantain (5000 PNU), fungi mixed (4000 PNU), Dermatophagoides pteronyssinus (3000 PNU), dog hair (4000 PNU), cat fur (4000 PNU) and feathers mixed (4000 PNU). All tests included positive $\left(1 \mathrm{mg} \mathrm{mL} \mathrm{m}^{-1}\right.$ histamine) and negative $(0.9 \%$ saline $)$ controls. Prick tests were considered positive if the mean wheal diameter $20 \mathrm{~min}$ after allergen application was at least $3 \mathrm{~mm}$ larger than the size of the negative control (Dreborg and Frew, 1993; Bousquet et al., 2012). Atopy was defined as the presence of at least one positive SPT to common inhalant allergens (Frew, 2003).

Spirometry: Spirometry, including measures of Forced Vital Capacity (FVC), $\mathrm{FEV}_{1}, \mathrm{FEV}_{1} / \mathrm{FVC}$ ratio and maximal expiratory flow at 50, 25 and $25-75 \%$ of FVC $\left(\mathrm{MEF}_{50}, \mathrm{MEF}_{25}\right.$ and $\mathrm{MEF}_{25-75}$, respectively), was performed in all subjects using spirometer PowerCubeSpiro for LF8 (Ganshorn Medizin Electronic GmbH, Germany) with recording the best result from three measurements the values of $\mathrm{FEV}_{1}$ of which were within $5 \%$ of each other. The results of spirometry were expressed as percentages of the predicted values according to the actual recommendations of European Repsiratory Society (ERS) and American Thoracic Society (ATS) (Miller et al., 2005; Clausen et al., 1997).

Histamine challenge: The histamine challenge test was performed according to the actual ERS/ATS recommendations (Sterk et al., 1993; Crapo et al., 2000). Concentrations of $0.5,1,2,4$ and $8 \mathrm{mg} \mathrm{mL}^{-1}$ histamine (Torlak, Beograd) were prepared by dilution with buffered saline. The doses of aerosol generated by 
Pari LC nebulizer with output rate $0.17 \mathrm{~mL} \mathrm{~min}^{-1}$ were inhaled by mouthpiece. Subjects inhaled increasing concentrations of histamine using a tidal breathing method until $\mathrm{FEV}_{1}$ fell by more than $20 \%$ of its base value (provocative concentration 20-PC20). The test was considered positive if PC20 was equal or less than $4 \mathrm{mg} \mathrm{mL}^{-1}$ (Sterk et al., 1993; Crapo et al., 2000).

According to the ATS recommendations, BHR was categorized as moderate to severe BHR (PC20 < $\left.1.0 \mathrm{mg} \mathrm{mL}^{-1}\right)$, mild BHR $\left(\right.$ PC20 $\left.=1.0-4.0 \mathrm{mg} \mathrm{mL}^{-1}\right)$ and borderline BHR (PC20>4.0 $\mathrm{mg} \mathrm{mL}^{-1}$ ) (Crapo et al., 2000).

Statistical analysis: Continuous variables were expressed as mean values with Standard Deviation (SD), whereas the nominal variables as numbers and percentages. Analyses of the data involved testing the differences in prevalence and comparison of the means. Chi-square test (or Fisher's exact test where appropriate) was used for testing difference in the prevalence. Comparison of spirometric measurements and PC20 values was performed by independentsamples T-test. A P-value less than 0.05 was considered as statistically significant. Statistical analysis was performed using the Statistical Package for the Social Sciences (SPSS) version 11.0 for Windows.

\section{RESULTS}

Demographic characteristics were similar in both H. pylori positive and negative subjects with allergic asthma (Table 1).

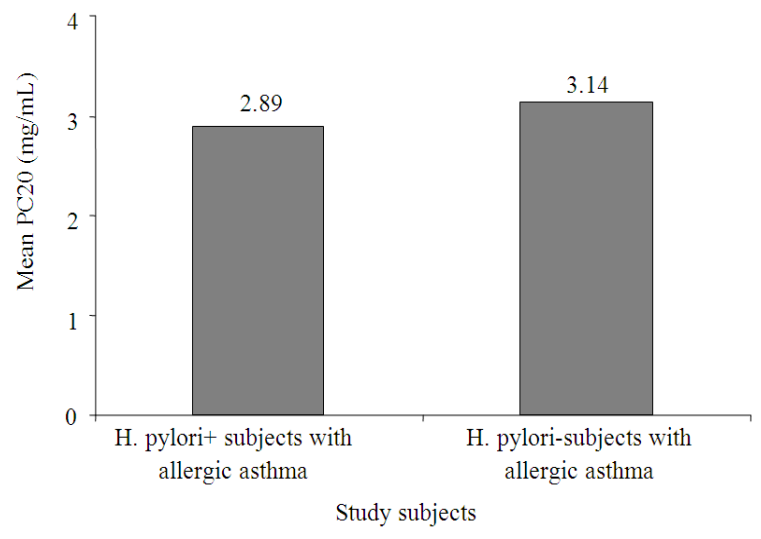

Fig. 1:Mean PC20 in H. pylori positive and H. pylori negative subjects with allergic asthma PC20: concentration of histamine causing a 20\% fall in FEV1; H. pylori: Helicobacter pylori
Sensitization to common inhalant allergens in the study subjects is given on Table 2. Mite sensitization was the most important individual common allergen with no statistical difference between sensitized subjects in both examined groups (Table 2).

Table 1: Demographics of the study subjects

\begin{tabular}{lll}
\hline $\begin{array}{l}\text { Common } \\
\text { inhalant } \\
\text { allergen }\end{array}$ & $\begin{array}{l}\text { H. pylori } \\
\text { positive subjects } \\
\text { with allergic } \\
\text { asthma (n=38) }\end{array}$ & $\begin{array}{l}\text { H. pylori } \\
\text { negative subjects } \\
\text { with allergic } \\
\text { asthma (n }=38)\end{array}$ \\
\hline $\begin{array}{l}\text { Males/females ratio } \\
\text { Age (years) }\end{array}$ & 0.9 & 0.9 \\
BMI (kg/m ${ }^{2}$ ) & $37.4 \pm 8.7$ & $37.8 \pm 7.5$ \\
$\begin{array}{l}\text { Mean IgG concentration } \\
\text { (U/mg) }\end{array}$ & $25.3 \pm 3.9$ & $25.7 \pm 5.1$ \\
Family history of asthma & $4(10.5 \%)$ & $0.5 \pm 0.1$ \\
Smoking status & & $3(7.9 \%)$ \\
Daily smokers & $10(26.3 \%)$ & $12(31.5 \%)$ \\
Smoking experience (years) & $17.8 \pm 5.7$ & $16.4 \pm 6.8$ \\
Cigarettes per day & $15.9 \pm 6.1$ & $14.8 \pm 5.9$ \\
Pack-years smoked & $12.3 \pm 3.7$ & $11.4 \pm 4.4$ \\
Ex-smokers & $3(7.9 \%)$ & $4(10.5 \%)$ \\
Passive smokers & $11(28.9 \%)$ & $9(23.7 \%)$ \\
Accompanying diseases & & \\
Arterial hypertension & $5(13.2 \%)$ & $3(7.9 \%)$ \\
Diabetes mellitus type 2 & $2(5.3 \%)$ & $3(7.9 \%)$ \\
\hline
\end{tabular}

Numerical data are expressed as mean value with standard deviation; frequencies as number and percentage of study subjects with certain variable. H. pylori: Helicobacter pylori; BMI: body mass index; kg: kilogram; m: meter; IgG: immunoglobulin G; U: unit; mg: miligram

Table 2:Sensitization to common inhalant allergens in both examined groups

\begin{tabular}{llll}
\hline & $\begin{array}{l}\text { H. pylori } \\
\text { positive subjects } \\
\text { with allergic } \\
\text { asthma }(\mathrm{n}=38)\end{array}$ & $\begin{array}{l}\text { H. pylori } \\
\text { negative subjects } \\
\text { with allergic } \\
\text { asthma }(\mathrm{n}=38)\end{array}$ & P-value * \\
inhalant allergen & $7(18.4 \%)$ & $5(13.2 \%)$ & 0.233 \\
Birch & $14(36.8 \%)$ & $11(28.9 \%)$ & 0.129 \\
Grass mixed & $9(23.7 \%)$ & $7(18.4 \%)$ & 0.217 \\
Plantain & $6(15.8 \%)$ & $7(18.4 \%)$ & 0.288 \\
Fungi mixed & $21(55.3 \%)$ & $23(60.5 \%)$ & 0.183 \\
D. pteronyssinus & $2(5.3 \%)$ & $3(7.9 \%)$ & 0.349 \\
Dog hair & $5(13.2 \%)$ & $4(10.5 \%)$ & 0.307 \\
Cat fur & $/$ & $/$ \\
Feathers mixed & $/$ & $/$ & \\
Data are expressed as number and percentage of the study subjects \\
with certain variable. H. pylori: Helicobacter pylori; D. \\
pteronyssinus: Dermatophagoides pteronyssinus. *Tested by chi- \\
square test (or Fisher's exact test where appropriate)
\end{tabular}

Table 3: Mean values of spirometric parameters in both examined groups

\begin{tabular}{llll}
\hline \multirow{2}{*}{$\begin{array}{l}\text { Spirometric } \\
\text { parameter }\end{array}$} & $\begin{array}{l}\text { H. pylori positive } \\
\text { subjects with allergic } \\
\text { asthma }(\mathrm{n}=38)\end{array}$ & $\begin{array}{l}\text { H. pylori negative } \\
\text { subjects with allergic }\end{array}$ & \\
\hline FVC (\%pred) & $89.7 \pm 10.8$ & $88.4 \pm 9.3$ & 0.105 \\
$\mathrm{FEV}_{1}$ (\%pred) & $81.6 \pm 7.9$ & $82.8 \pm 10.2$ & 0.131 \\
$\mathrm{FEV}_{1} /$ FVC\% & $77.8 \pm 6.7$ & $78.4 \pm 8.1$ & 0.226 \\
$\mathrm{MEF}_{50}$ (\%pred) & $68.9 \pm 16.3$ & $66.5 \pm 12.9$ & 0.144 \\
$\mathrm{MEF}_{25}$ (\%pred) & $63.2 \pm 17.1$ & $64.6 \pm 14.8$ & 0.162 \\
$\mathrm{MEF}_{25-75}$ (\%pred) & $78.2 \pm 15.8$ & $76.4 \pm 12.2$ & 0.129 \\
\hline
\end{tabular}

Data are expressed as mean value with standard deviation. H. pylori: Helicobacter pylori; FVC: forced vital capacity; $\mathrm{FEV}_{1}$ : forced expiratory volume in one sec; $\mathrm{MEF}_{50}, \mathrm{MEF}_{25}, \mathrm{MEF}_{25-75}$ : maximal expiratory flow at 50,25 and $25-75 \%$ of FVC, respectively; \% pred: $\%$ of predicted value. *Compared by independent-samples T-test. 
We found similar mean values of spirometric parameters in both examined groups (Table 3 ).

We found lower BHR severity (expressed as a mean PC20) in $\mathrm{H}$. pylori positive than in $\mathrm{H}$. pylori negative subjects with allergic asthma, but the difference was statistically non-significant $(2.89 \mathrm{mg}$ $\mathrm{mL}^{-1}$ Vs $3.14 \mathrm{mg} \mathrm{mL} \mathrm{m}^{-1}, \mathrm{p}=0.117$; independentsamples T-test) (Fig. 1).

\section{DISCUSSION}

According to the results of several studies $H$. pylori infection is associated with polarization of immune system with decreased risk for development of asthma and associated allergic disease (Cremonini and Gasbarrini, 2003; Shiotani et al., 2008). Results from the Bristol Helicobacter Project indicated that $\mathrm{H}$. pylori infection is associated with substantially reduced risk for three atopic diseases (asthma, allergic rhinitis and atopic deramtitis) (McCune et al., 2003). However, results of some other studies did not find significant difference in levels of $\mathrm{H}$. pylori antibodies in studies of atopy, asthma and wheezing (Jun et al., 2005; Cam et al., 2009).

On the other side, it has been suggested that exposure to $H$. pylori is associated with a decrease in lung function and may be a contributing risk factor for chronic Obstructive Pulmonary Disease (COPD) (Roussos et al., 2003). In the present study including $H$. pylori positive and negative subjects with allergic asthma we assessed the impact of exposure to $H$. pylori on lung function parameters and BHR severity. The examined groups included subjects with similar demographic characteristics. In either group there was a large proportion of daily and passive smokers, as well as a low proportion of ex-smokers, that is similar to its prevalence in R. Macedonia documented in our previous studies (Minov et al., 2006; 2008) and indicate still insufficient anti-smoking activities.

Mite sensitization and grass pollens were the most important common inhalant allergens in the subjects of both examined groups. Similar pattern of allergic sensitization was also registered in our previous studies on allergic asthma among adults in R. Macedonia (Minov et al., 2003; Karadzinska-Bislimovska et al., 1999).

Adult lung function is a consequence of the peak lung growth attained by the third decade and the subsequent rate of lung function decline occurring in the subsequent adult life (Sherill et al., 1989; Hole et al., 1996). As it was mentioned above $H$. pylori infection is associated with growth delay in children and has a negatively impact on lung development and lower lung function (Perri et al., 1997; Hankinson et al., 1999). In the present study we found similar mean values of $\mathrm{FVC}, \mathrm{FEV}_{1}$ and $\mathrm{FEV}_{1} / \mathrm{FVC}$ ratio, as well as of MEF parameters, in both examined groups. Similar findings were reported by Fullerton et al. (2009) in their population-based study in adults that investigated impact of exposure to $H$. pylori on lung function, atopy and asthma. Namely, in cross-sectional analysis they found lower lung function as measured by FVC and $\mathrm{FEV}_{1}$ but this association disappeared after statistical adjustment for either height or socio-economic status. In addition, longitudinally analysis indicated that $H$. pylori serological status had no effect on the decline in lung function over 9 years.

$\mathrm{BHR}$, defined as an exaggerated response to the bronchoconstrictor (including pharmacological agents, non-isotonic aerosols, cold air, exercise, environmental allergens and occupational sensitizers) is one of the key features of asthma (Sterk and Bel, 1989; Joos and O'Connor, 2003). BHR is not specific only for asthma and may occur in the course of other diseases, such as COPD, allergic rhinitis, atopic dermatitis, cystic fibrosis and congestive heart failure (Bel and Chanez, 2003; Tashkin et al., 1992). The hyperreactivity of the airways in subjects with asthma is related to the degree of allergic inflammation, as measured by histamine or metacholine challenge (Barnes, 2003). In contrast to COPD, BHR in subjects with asthma is not related to the basic $\mathrm{FEV}_{1}$ value and has higher severity (moderate to severe and mild BHR) which is related to blood eosinophil count and total serum Immunoglobuline E (IgE) (Josephs et al., 1990). In the study of (Fullerton et al., 2009), mentioned above the authors found similar prevalence of BHR (defined as a provocative dose causing $\mathrm{FEV}_{1}$ fell by more than $20 \%$ of its base value-PD20) in subjects with positive and negative serology for $H$. pylori (Hole et al., 1996). In the present study we found lower degree of BHR severity in $H$. pylori positive than in $H$. pylori negative subjects with allergic asthma but the difference did not reach statistical significance.

The present study has some limitations. First, relatively small number of the subjects in the study groups could have certain implications on the data obtained and its interpretation. Second, the study design, i.e., cross-sectional analysis, could also have implications on the data obtained and its interpretation. Third, the serological data for exposure to $H$. pylori is unable to distinguish current from prior infection which limits interpretation of the associations observed. The strength of the study is the comparison of the degree of BHR severity between subjects with allergic asthma with positive and negative serology for $H$. pylori that, to our knowledge, so far has not been reported in published literature. 


\section{CONCLUSION}

In conclusion, in a cross-sectional study including H. pylori positive and negative subjects with allergic asthma we found similar mean values of spirometric parameters, as well as similar degree of BHR severity, in both examined groups. Our findings support the need of further larger prospective studies in order to assess the complex relationship between $H$. pylori infection and development and manifestations of allergic asthma.

\section{REFERENCES}

Amedei, A., A. Cappon, G. Codolo, A. Cabrelle and A. Polenghi et al., 2006. The neutrophil-activating protein of Helicobacter pylori promotes Th1 immune response. J. Clin. Invest., 116: 1092-1101. DOI: $10.1172 / \mathrm{JCI} 27177$

Ball, T.M., J.A. Castro-Rodriguez, K.A. Griffith, C.J. Holberg and F.D. Martinez et al., 2000. Siblings, day-care attendance and the risk of asthma and wheezing during childhood. N. Eng. J. Med., 343: 538-543.

Barnes, P.J., 2003. Pathophysiology of asthma. Eur. Respir. Mon., 42: 3-136. DOI: 10.1046/j.13652125.1996.03721.x

Bateman, E.D., S.S. Hurd, P.J. Barnes, J. Bousquet and J.M. Drazen et al., 2008. Global strategy for asthma management and prevention: GINA executive summary. Eur. Reapir. J., 31: 1143-1178. DOI: 10.1183/09031936.00138707

Bel, E.H. and P. Chanez, 2003. Diagnosis and assessment of asthma. Eur. Respir. Mon., 8: 180-194.

Blaser, M.J., Y. Chen and J. Reibman, 2008. Does Helicobacter pylori protect against asthma and allergy? Gut, 57: 561-567. DOI: 10.1136/gut.2007.133462

Bousquet, J., L. Heinzerling, C. Bachert, N.G. Papadopoulos and P.J. Bousquet et al., 2012. Practical guide to skin prick tests in allergy to aeroallergens. Allergy, 67: 18-24. DOI: 10.1111/j.1398-9995.2011.02728.x

Cam, S., D. Ertem, N. Bahceciler, T. Akkoe and I. Barlan et al., 2009. The interaction between helicobacter pylori and atopy: Does inverse association really exist? Helicobacter, 14: 1-8. DOI: 10.1111/j.1523-5378.2009.00660.x

Clausen, J.L., A.L. Coates and P.H. Quanjer, 1997. Measurement of lung volumes in humans: Review and recommendations from an ATS/ERS workshop. Eur. Respir. J., 10: 1205-1206. DOI: 10.1183/09031936.97.10061205

Codolo, G., P. Mazzi, A. Amedei, G.D. Prete and G. Berton et al., 2008. The neutrophil-activating protein of Helicobacter pylori down-modulates Th2 inflammation in ovalbumin-induced allergic asthma. Cell Microbiol., 10: 2355-2363. DOI: 10.1111/j.1462-5822.2008.01217.x
Crapo, R.O., R. Casaburi, A.L. Coates, P.L. Enright and J.L. Hankinson, 2000. Guidelines for methacholine and exercise challenge testing-1999. Am. Respir. Crit. Care Med., 161: 309-329. PMID: 10619836

Cremonini, F. and A. Gasbarrini, 2003. Atopy, Helicobacter pylori and the hygiene hypothesis. Eur. J. Gastroenterolo Hepatol., 15: 635-636.

D'Elios, M.M., G. Codolo, A. Amedei, P. Mazzi and G. Berton et al., 2009. Helicobacter pylori, asthma and allergy. FEMS Immunol. Med. Microbiol., 56: 1-8. DOI: 10.1111/j.1574-695X.2009.00537.x

D'Elios, M.M., M. Manghetti, M.D. Carli, F. Costa and C.T. Baldari et al., 1997. T helper 1 effector cells specific for Helicobacter pylori in the gastric antrum of patients with peptic ulcer disease. J. Immunol., 158: 962-967.

Dreborg, S. and A. Frew, 1993. Position paper: Allergen standardization and skin tests. Allergy, 48: $\quad 9-82 . \quad$ DOI: $\quad 10.1111 / \mathrm{j} .1398-$ 9995.1993.tb04756.x

Frew, A.J., 2003. Allergic basis of asthma. Eur. Respir. Mon., 23: 74-83.

Fullerton, D., J.R. Britton, S.A. Lewis, I.D. Pavord and T.M. McKeever et al., 2009. Helicobacter pylori and lung function, asthma, atopy and allergic disease-A population-based cross-sectional study in adults. Int. J. Epidemiol., 38: 419-426. DOI: 10.1093/ije/dyn348

Hankinson, J.L., J.R. Odencrantz and K.B. Fedan, 1999. Spirometric reference values from a sample of the general U.S. population. Am. J. Respir. Crit. Care Med., 159: 179-187.

Hole, D.J., G.C.M. Watt, G. Davey-Smith, C.L. Hart and C.R. Gillis et al., 1996. Impaired lung function and mortality risk in men and women: Findings from the Renfrew and Paisley prospective population study. Br. Med. J., 313: 711-715.

Joos, G.F. and B. O'Connor, 2003. Indirect airway challenges. Eur. Respir. J., 21: 1050-1068. DOI: 10.1183/09031936.03.0000

Josephs, L.K., I. Gregg and S.T. Holgate, 1990. Does non-specific bronchial responsiveness indicate the severity of asthma? Eur. Respir. J., 3: 220-227.

Jun, Z.J., Y. Lei, Y. Shimizu, K. Dobashi and M. Mori, 2005. Helicobacter pylori seroprevalence in patients with mild asthma. Tohoku J. Exp. Med., 207: 287-291. DOI: 10.1620/tjem.207.287

Karadzinska-Bislimovska, J., V. Cvetanov, J. Petrovska, S. Todorov and S. Risteska-Kuc, 1999. Respiratory symptoms and positive skin prick test in a prospective asthma study in Republic of Macedonia (initial results). Eur. Respir. J., 14: 78-78. 
Matricardi, P.M., F. Rosmini, S. Riondino, M. Fortini and L. Ferrigno, 2000. Exposure to foodborne and orofecal microbes versus airborne viruses in relation to atopy and allergic asthma: Epidemiological study. BMJ., 320: 412-417. DOI: 10.1136/bmj.320.7232.412

Matricardi, P.M., F. Rosmini, V. Panetta, L. Ferrigno and S. Bonini, 2002. Hay fever and asthma in relation to markers of infection in the United States. J. Allergy Clin. Immunol., 110: 381-387.

McCune, A., A. Lane, L. Murray, I. Harvey and P. Nair et al., 2003. Reduced risk of atopic disorders in adults with Helicobacter pylori infection. Eur. J. Gastroenterol. Hepatol., 15: 637-640.

Miller, M.R., J. Hankison, V. Brusasco, F. Burgos and R. Casaburi et al., 2005. Standardization of spirometry. Eur. Respir. J., 26: 319-338. DOI: 10.1183/09031936.05.00034805

Minov, J., J. Karadzinska-Bislimovska, K. Vasilevska, S. Risteska-Kuc and S. Stoleski, 2008. Exposure to environmental tobacco smoke in the workplace in Macedonia: Where are we now? Arh. Hig Rada Toksikol., 59: 103-109. PMID: 18573747

Minov, J., J. Karadzinska-Bislimovska, K. Vasilevska and S. Stoleski, 2006. Smoking status in exposed and unexposed workers. Mak. Med. Pregled., 60: 128.

Minov, J., V. Cvetanov, J. Karadzinska-Bislimovska, N. Ezova and S. Milkovska et al., 2003. Epidemiological characteristics of bronchial asthma in R. Macedonia. Mak Med. Pregled., 56: 156-156.

Mutius, E.V. and M.R. Sears, 2003. Risk factors for development of asthma. Eur. Respir Mon., 8: 57-74.

Parsonnet, J., G.D. Friedman, D.P. Vandersteen, Y. Chang and J.H. Vogelman et al., 1991. Helicobacter pylori infection and the risk of gastric carcinoma. New Eng. J. Med., 325: 1127-1131.

Pavord, I.D., S.S. Birring, M. Berry, R.H. Green and C.E. Brightling et al., 2006. Multiple inflammatory hits and the pathogenesis of severe airway disease. Eur. Respir. J., 27: 884-888. DOI: 10.1183/09031936.06.00128105

Perri, F., M. Pastore, G. Leandro, R. Clemente and Y. Ghoos et al., 1997. Helicobacter pylori infection and growth delay in older children. Arch. Dis. Child, 77: 46-49. DOI: 10.1136/adc.77.1.46
Roussos, A., N. Philippou and K.I. Gourgoullanis, 2003. Helicobacter pylori infection and respiratory diseases: A review. World J. Gastroenterol., 9: 5-8.

Salvi, S.S., A. Frew and S. Holgate, 1999. Is diesel exhaust a cause for increasing allergies? Clin. Exp. Allergy, 29: 4-8. DOI: 10.1046/j.13652222.1999.00465.x

Sherill, D.L., A. Camilli and M.D. Lebowitz, 1989. On the temporal relationships between lung function and somatic growth. Am. Rev. Respi. Dis., 140: 638-644. DOI: 10.1164/ajrccm/140.3.638

Shiotani, A., T. Miyanishi, T. Kamada and K. Haruma, 2008. Helicobacter pylori infection and allergic diseases: Epidemiological study in Japanese university students. J. Gastroenterol. Hepatol., 23: e29-33. DOI: 10.1111/j.1440-1746.2007.05107.x

Sterk, P.J. and E.H. Bel, 1989. Bronchial hyperresponsiveness: The need for a distinction between hypersensitivity and excessive airway narrowing. Eur. Respir. J., 2: 267-274.

Sterk, P.J., L.M. Fabbri, P.H. Quanjer, D.W. Cockcroft and P.M. O'Byrne et al., 1993. Airway responsiveness. Standardized challenge testing with pharmacological, physical and sensitizing stimuli in adults. Report Working Party Standardization of Lung Function Tests, European Community for Steel and Coal. Official Statement Eur. Respir. Soc. Eur. Respir. J., 6: 58-83.

Tashkin, D.P., M.D. Alose and E.R. Bleecker, 1992. The lung health study: Airway responsiveness to inchalant metacholine in smokers with mild to moderate airway limitation. The lung health study research group. Am. Rev. Respir. Dis., 145: 301310.

Wotherspoon, A.C., C. Ortiz-Hidalgo, M.R. Falzon and P.G. Isaacson, 1991. Helicobacter pyloriassociated gastritis and primary B-cell gastric lymphoma. Lancet, 338: 1175-1176. DOI: 10.1016/0140-6736(91)92035-Z 